
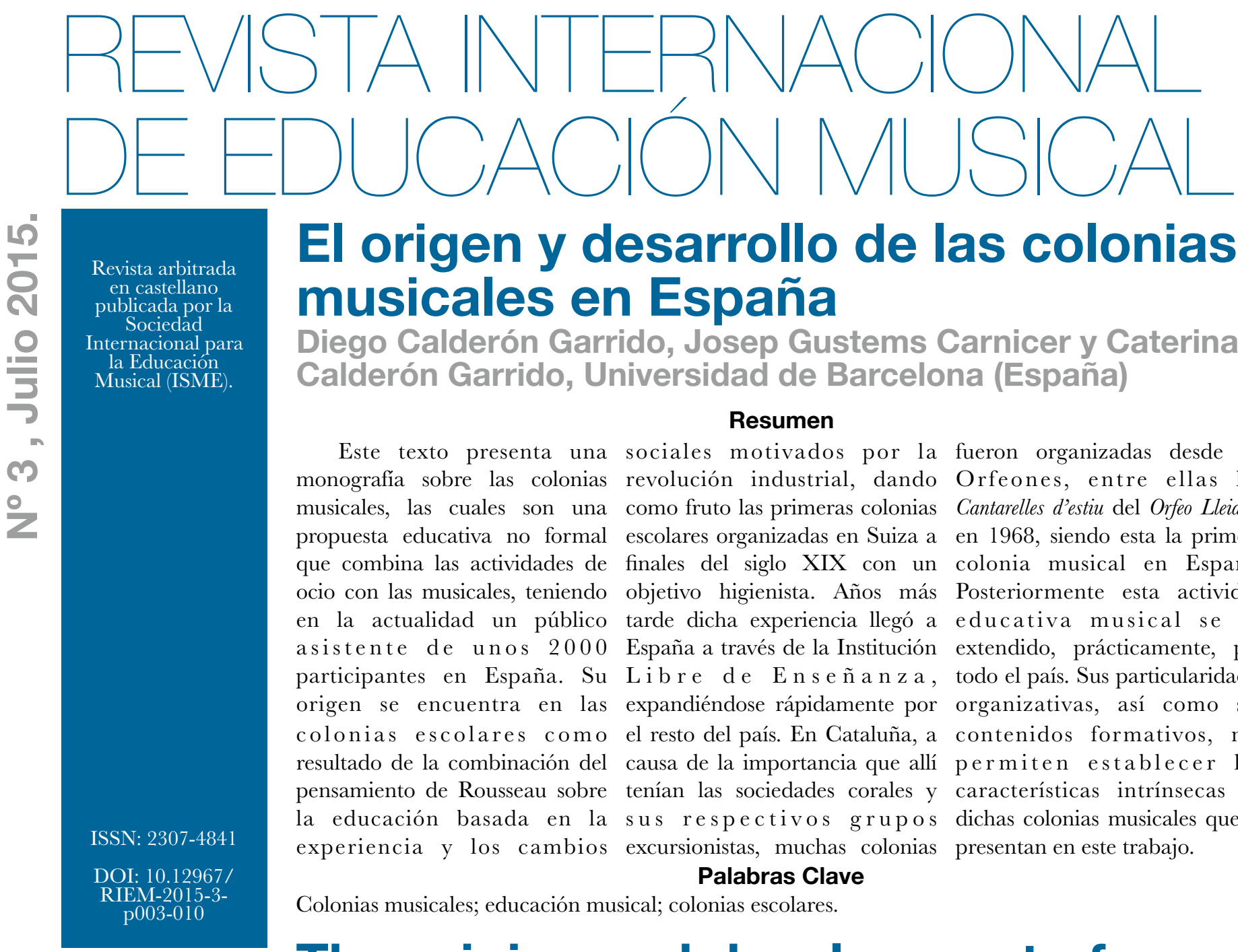

\title{
El origen y desarrollo de las colonias musicales en España
}

\section{Diego Calderón Garrido, Josep Gustems Carnicer y Caterina Calderón Garrido, Universidad de Barcelona (España)}

\section{Resumen}

Este texto presenta una sociales motivados por la fueron organizadas desde los monografía sobre las colonias revolución industrial, dando Orfeones, entre ellas los musicales, las cuales son una como fruto las primeras colonias Cantarelles d'estiu del Orfeo Lleidatà propuesta educativa no formal escolares organizadas en Suiza a en 1968, siendo esta la primera que combina las actividades de finales del siglo XIX con un colonia musical en España. ocio con las musicales, teniendo objetivo higienista. Años más Posteriormente esta actividad en la actualidad un público tarde dicha experiencia llegó a educativa musical se ha asistente de unos 2000 España a través de la Institución extendido, prácticamente, por participantes en España. Su Libre de Enseñ a n z a, todo el país. Sus particularidades origen se encuentra en las expandiéndose rápidamente por organizativas, así como sus colonias escolares como el resto del país. En Cataluña, a contenidos formativos, nos resultado de la combinación del causa de la importancia que allí permiten establecer las pensamiento de Rousseau sobre tenían las sociedades corales y características intrínsecas de la educación basada en la sus respectivos grupos dichas colonias musicales que se experiencia y los cambios excursionistas, muchas colonias presentan en este trabajo.

\section{Palabras Clave}

Colonias musicales; educación musical; colonias escolares.

\section{The origins and development of music camps in Spain \\ Diego Calderón Garrido, Josep Gustems Carnicer y Caterina Calderón Garrido, Barcelona University (Spain)}

\section{Abstract}

This paper delves with camps in Switzerland in the late d'estiu by l'Orfeo Lleidatà in 1968, music camps, a non-formal $19^{\text {th }}$ Century, with a hygienist being the first music camp in educational approach that target. Years later that Spain. Later this musical combines leisure activities with experience came to Spain educational activity has spread music, currently taking about through the Institución Libre de virtually throughout the country. 2000 students in Spain. Its origin Enseñanza, expanding rapidly Th e i r o r g a n i zat i o n a l is in the school camps, resulting through the rest of the country. characteristics, as well as their from the combination of In Catalonia, because of the educational content, allow us to Rousseau's thought on education importance that choral societies establish the intrinsic based on experience with social and their respective hiking characteristics of these music changes brought about by the groups had there, many colonies camps presented in this work. industrial revolution, giving as a were organized from the result the first organized school choruses, including Cantarelles

\section{Keywords}

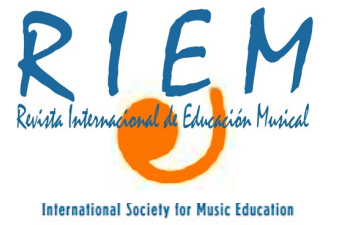

ISMEO

Established in 1953 )

Music camps; music education; school camps. 


\section{El origen y desarrollo de las colonias musicales en España}

por Diego Calderón Garrido, Josep Gustems Carnicer y Caterina Calderón Garrido, Universidad de Barcelona (España)

El objetivo de este trabajo es mostrar los orígenes y posterior desarrollo de las colonias musicales en España. Esto nos ayudará a entender las características intrínsecas que esta actividad educativa tuvo en sus inicios y, a través de un análisis de su evolución, su valor y características actuales.

Las colonias musicales ${ }^{1}$ se nos presentan como un espacio educativo no formal en el que se combinan actividades de ocio y musicales, de forma parecida a como ocurre con el resto de colonias de carácter específico, como deportivas, de idiomas, etc. (Trilla, Gros, López y Martín, 1993). En la actualidad en España están implicados aproximadamente 2000 alumnos entre 6 y 17 años procedentes preferentemente de Educación Secundaria con estudios elementales de escuela de música, 145 profesores de música y 100 monitores en esta experiencia.

Estas colonias musicales presentan, además, unos objetivos pedagógicos que se centran tanto en la asimilación y desarrollo de aptitudes técnico-profesionales desde el ámbito de la música, como en el ámbito de las actividades guiadas de tiempo libre. Además de dichos objetivos, se observa un refuerzo en el desarrollo de competencias personales y sociales, ya sea desde las clases de música, o mediante las actividades guiadas de tiempo libre.

\section{El origen de las colonias escolares}

La aparición y posterior expansión de las colonias escolares, surgidas en el último tercio del siglo XIX por toda Europa y algunos países americanos, se nos presenta, al menos en sus orígenes, como una actividad extraescolar dirigida al sector más joven y desfavorecido de la sociedad, con un marcado objetivo en la mejora de la salud, higiene y formación de los más necesitados (Campos, 1995). En definitiva, la base de esta actividad era la protección de la infancia.

Para analizar los factores que dieron como resultado las colonias, debemos tener en cuenta dos aspectos fundamentales: el primero de ellos es el desarrollo de la sociedad industrial y los cambios económicos, políticos y sociales que esto acarreó, incluyendo el crecimiento desmesurado de las urbes y el hacinamiento y pobreza de muchos habitantes (Terrón, 2000); el segundo consiste en la aparición una nueva corriente educativa basada en los pensamientos de Rousseau sobre el aprendizaje a través de la experiencia. Dicho autor consideraba favorables los ejercicios físicos y las excursiones, tomando como principios fundamentales el respeto por el desarrollo personal de la naturaleza individual y la concepción integral de la educación, la cual debe atender a las necesidades del hombre en sus dimensiones físicas, intelectuales y morales (Rousseau, 2000), pilares que sustentan la base de las actividades extraescolares.

La conjunción de los factores recién descritos propició el nacimiento de las colonias escolares. En ellas se reconoció la necesidad de combinar educación e higiene en la infancia y la adolescencia. Al tratarse de niños, la organización y el cuidado estuvo en manos de maestros, por lo que los aspectos pedagógicos adquirieron especial protagonismo, a pesar de que en numerosas ocasiones éstos tuvieron que encargarse de cubrir las necesidades básicas sanitarias y de alimentación, y no de las labores educativas habituales.

\section{Las primeras colonias escolares}

Los primeros antecedentes relacionados directamente con las colonias escolares se remontan a 1795, cuando el diputado francés Louis Portier argumentaba en un discurso delante de la Convención Nacional de su país que "el propósito es trasladar la escuela a un puerto de mar o al campo, medio que sería excelente para desenvolver las facultades morales e intelectuales de los niños, de formar su corazón, de fortificar su cuerpo" (Vilariño, 1930, p. 31). Aunque estas ideas no se llevaron a la práctica, sí tuvieron una notable influencia futura en diversos países europeos como Inglaterra, Dinamarca y España, los cuales protagonizaron los primeros intentos de actividades parecidas a las colonias. En cualquier caso, estas experiencias, dirigidas a la nueva burguesía (Rodríguez Pérez, 2001) fijaron los cimientos de las reconocidas como primera colonia escolar: la realizada por el pastor protestante Walter Bión en 1876. Éste, acompañado de otros 10 maestros y maestras, trasladó a 68 niños y niñas durante 14 días desde la ciudad de Zúrich a las montañas del cantón suizo de Appenzell a disfrutar del aire puro y de un alimento sano. Estos primeros colonos fueron agrupados en secciones de 20 a 30 menores, los cuales estuvieron bajo la dirección continua de los maestros acompañantes (Bión, 1887).

Esta primera experiencia tuvo repercusión internacional, llegando a España a través de la Institución Libre de Enseñanza, la cual creó, posteriormente, el Museo Pedagógico Nacional. La labor principal de dicho Museo fue la de dar a conocer los avances internacionales realizados en pedagogía, entre los que estaban las colonias de Bión. En definitiva, el Museo era un lugar para ayudar al maestro, "un laboratorio de experiencias que serviría para intercambiar ideas, promover reuniones y excitar el avance científico de la enseñanza" (Nogués, 1977, p. 200).

En cualquier caso, tanto el director de la Institución, Francisco Giner de los Ríos, como el del Museo, Manuel Bartolomé Cossio, mostraron una gran preocupación por la mejora de la salud y las costumbres higiénicas del pueblo a través del ejercicio físico y el aire libre (Pereyra, 1982). Dicho interés por el aire libre transformó la idea de que sólo lo que ocurre en clase es importante, trasgrediendo así los limites físicos de las escuelas y realizando innumerables excursiones (Molero, 2000). Dichas excursiones tuvieron su máximo exponente con la organización, en 1887, de las primeras colonias en España. De estas colonias se beneficiaron 18 niños madrileños entre 9 y 13 años de edad, los cuales fueron conducidos durante un mes a la localidad costera de San Vicente de la Barquera, en Cantabria (Nogués, 1977).

Los resultados de estas primeras colonias fueron respaldados por las diferentes políticas institucionales, las cuales incentivaron la organización de nuevas colonias por todo el territorio nacional, extendiéndose dicha oferta formativa por todas las regiones (Pereyra, 1982), 
especialmente en toda la zona mediterránea (Galí, 1979) e incrementándose exponencialmente el número de alumnos participantes.

Posteriormente, los diferentes cambios políticos acaecidos en España en las décadas de los años 30 y 70 , respaldaron las colonias escolares de forma diferente, pero alabando siempre los beneficios que estas conllevaban, auspiciando en todo momento su organización y difusión. Así pues, durante la II República se construyeron muchos albergues destinados a la realización de colonias, y durante el franquismo el movimiento de colonias pasó a utilizarse de forma partidista. Más tarde, con la instauración de la democracia, se han popularizado y diversificado las diferentes tipologías de colonias, tales como las deportivas, las de idiomas, las artísticas, etc. (Calderón, 2015).

\section{Contenidos musicales en las colonias escolares}

El desarrollo artístico, a través de diferentes actividades, ha estado siempre ligado a las colonias escolares. Así por ejemplo, las artes literarias se han visto potenciadas por el «diario de la colonia» que acompañaba a los menores desde las primeras experiencias; las artes visuales se desarrollaban a través de los dibujos de la naturaleza que los colonos realizaban en sus excursiones; las artes escénicas se desarrollaron a través de las obras de teatro y diferentes representaciones realizadas durante las actividades de tiempo libre; y, finalmente, las artes musicales, tal como veremos a continuación, han sido una constante desde los orígenes de las colonias (Calderón y Gustems, 2012). De esta forma podemos afirmar que la música, y en concreto el canto, ha sido el denominador común en todas ellas, ya que los beneficios que éste tenía en las colonias escolares y sus participantes no pasaron desapercibidos para sus organizadores, que siempre consideraron tales efectos como algo básico en el funcionamiento de la colonia ya que se trataba de una actividad que les acompañaba y adaptaba tanto a los momentos de excitación como de sosiego, propiciando, además, el gusto y desarrollo por las actividades artísticas $^{2}$ :

Al regreso del paseo o excursión de la tarde dedican, en algunas colonias, un rato al canto, aunque puede suceder muchas veces que el regreso sea tarde y no haya tiempo para esta tarea tan agradable a los niños. Por eso, el buen juicio de los maestros puede determinar el momento oportuno, que puede ser en los momentos de descanso en el paseo o excursión, cuando los niños están demasiado excitados, por el efecto sedante que el canto produce

(Monroy, 1918, p. 9).

En esta línea, y realizando un brevísimo recorrido histórico, observamos propuestas como la del Ayuntamiento de Barcelona que encargó en 1908 la composición de un himno para las colonias que pudiese interpretarse en todas las actividades de este tipo organizadas por dicho Ayuntamiento; o, por ejemplo, en el caso de las colonias fundadas por el Museo Pedagógico Nacional, hay constancia de las visitas que Gustave Koeckert hizo entre 1912 y 1914 desde Suiza para preparar y dirigir los coros que se organizaban (Nogués, 1977); o el caso de Artur Martorell, quien en 1923 organizaba conciertos de destacados interpretes de la época para los asistentes a la colonia (Tarín, 1968). Más adelante, en la etapa franquista se consideraba que la música tenía influencia directa sobre el espíritu y que "la unidad de las tierras españolas (que en lo militar estaba siendo obra del Caudillo y de su ejercito) sería conseguida a través de la doctrina nacionalsindicalista, de la tierra, y de la música" (Luengo, 1995, p. 53), realizándose manuales en los cuales se incluían las canciones que se debían cantar. A modo de ejemplo, incluimos la siguiente introducción de uno de dichos manuales:

Para ti camarada que asistes a nuestras Marchas y Campamentos, son estas canciones.

Te harán conocer los himnos heroicos de la Falange, letras de amor y guerra, música de compás marcial y alegre que son imprescindibles para marchar codo a codo con tus camaradas, con el estilo que nos impone nuestra alegre disciplina y nuestro juvenil optimismo.

Llévalas contigo siempre y canta todas las veces que puedas, canta alegre y virilmente, como únicamente lo saben hacer los individuos sanos y los pueblos vencedores (Frente de Juventudes, 1945, p. 3).

De esta forma observamos cómo las canciones se consideraban parte indispensable en el funcionamiento de la colonia y del sentimiento de unidad que se intentaba transmitir. Servían igualmente para transmitir el espíritu que el Régimen buscaba inculcar en los jóvenes españoles.

Posteriormente, con la llegada de la democracia, las colonias escolares se adaptaron a la diversificación de los intereses sociales, surgiendo nuevas tipologías: colonias de idiomas, deportes, tecnología, etc. (Calderón y Gustems, 2012). A su vez, se legisló quién y cómo se haría cargo de los menores asistentes a las colonias, profesionalizándose la figura de las personas responsables de los menores en las colonias, en este caso los monitores de tiempo libre. Dichos monitores tienen, en su formación, nociones básicas sobre música, que incluyen el aprendizaje de canciones y nociones sobre instrumentos de acompañamiento, principalmente guitarra. De esta forma, la música ha seguido presente en las colonias escolares.

\section{Precedentes de las colonias musicales en España}

Si bien la progresiva especialización de las colonias hacia diferentes áreas temáticas permite en la actualidad la existencia de múltiples actividades enfocadas a diversos intereses concretos, la publicidad ha hecho que la misma actividad reciba nombres diversos (tales como colonia, curso, campamento, etc.) que guardan algunas características comunes. En este sentido, y para poder concretar el nacimiento de las colonias musicales, debemos establecer un criterio que permita diferenciar éstas de otras actividades similares. Así pues, cuando hablamos de «colonias musicales» nos referiremos a actividades que se desarrollan durante el periodo estival, en un albergue o similar, donde un grupo de alumnos reciben clases de música de profesores cualificados, y son guiados en sus actividades de ocio por monitores de tiempo libre, conviviendo todos ellos durante dicha colonia (Calderón, 2015).

Para poder buscar los orígenes de las colonias musicales en España, debemos entender la conjunción de, por un lado, la relevancia que las sociedades corales tuvieron en Cataluña a principios del s. XX, siendo estas durante el reinado de Isabel II "el segundo grupo por importancia de las asociaciones censadas" (Guereña, 1998, p. 10) y, por otro, la actividad de colonias, que tal como hemos descrito se desarrolló especialmente en la costa mediterránea. La combinación entre los dos factores comentados actuó como catalizador de las múltiples actividades referentes a las 
colonias organizadas por las asociaciones musicales como, por ejemplo, el Orfeó Terrassa y las actividades de su grupo excursionista. Este orfeón organizó en 1929 una colonia de tres días en Zaragoza y en la cual participaron las familias que pertenecían al mismo (Orfeó de Terrassa, 1929).

A pesar de esto, y después de un profundo análisis de las colonias en sus diferentes épocas, así como de las actividades que en ellas se desarrollaban, los aspectos relativos a los menores asistentes y el personal docente, podemos afirmar que el precedente más claro de colonias musicales a nivel nacional son las organizadas por el Orfé Gracienc de Barcelona entre 1933 y 1935 financiadas, en parte, por el emblemático Pau Casals (Jou, 1933; Soler i Borrel, 1935). Sin entrar en detalles sobre dicha colonia, los 17 colonos asistentes a su primera edición - pertenecientes a la sección infantil del Orfé Gracienc-, además del resto de actividades propias de las colonias escolares, ensayaron durante dos días junto a Joan Balcells -director del orfeón- para ofrecer un concierto durante la ceremonia eclesiástica con motivo de la fiesta mayor del pueblo donde realizaron la colonia (Las Franquesas del Vallés, Barcelona). Dicho ensayo y la posterior interpretación de canciones propias del culto, permite distinguir esta colonia del resto, reafirmándonos en la etiqueta de «precedente» de las colonias musicales en España.

La Guerra Civil interrumpió drásticamente todas las colonias, postergando hasta varios años después del asentamiento del régimen franquista la normalidad en su organización.

\section{La primera colonia musical en España}

En el caso de Cataluña, dicha normalización vino reflejada por los cambios sociales acaecidos, especialmente, a partir de 1959 con el inicio del denominado «segundo franquismo» y el Plan de Estabilización propugnado desde el Gobierno Central. Con el mismo se retomaron espacios culturales en los que la lengua catalana volvió a ser el protagonista, tales como sesiones de teatro, lectura de poesía, cine-fórum, conciertos de la Nova Cançó, etc. (Estivill i Rius, 2013). En este intento de recuperación cultural, el papel de las sociedades corales retomó la importancia de la cual habían gozado en años anteriores. Entre dichas sociedades, y debido a la importancia que tiene para nuestra investigación, destacaremos al Orfé Lleidatà y a su director Lluís Virgili.

Virgili, ligado a la Escolanía de Montserrat entre 1934 y 1936, se especializó en educación musical y dirección coral, además de tener una fuerte implicación política, llegando a ser diputado al Parlamento de Cataluña en las elecciones de 1980 en representación de la coalición CIU (Convergència $i$ Unió) por la provincia de Lérida. Su inclinación pedagógica, propició la creación de una escuela de música dependiente del Orfeó Lleidatà en 1962. Previamente a esto, la entidad había creado en 1958 el Centre d'Art Fuvenil, con el objetivo de facilitar a niños y jóvenes formación sobre las costumbres, la historia y el idioma, a través de la música y del canto coral (Orfeó Lleidatà, 2011).

El interés por la educación coral llevaron a Virgili a organizar en 1963 el I Curs Internacional de Direcció Coral $i$ Pedagogia Musical Infantil. A dicho curso asistían profesores franceses ${ }^{3} y$, a pesar de no existir constancia de que estos cursos incidiesen de forma directa en la gestación de las colonias que ahora describiremos, sí es cierto que en dichos cursos existía un contacto con las corrientes pedagógicas europeas y las experiencias francesas, las cuales pudieron influir en la idea base de dicha organización (Orfeó Lleidatà, 1985).

Virgili también mostró interés por el excursionismo y las actividades de colonias, de tal forma que en 1967, pidió prestadas unas tiendas de campaña al ejército para trasladarse a Ulldemolins (Tarragona) con unos cuantos alumnos menores de edad del orfeón, sin ninguna pretensión de realizar actividades musicales, sino buscando un contacto con la naturaleza. Las condiciones del lugar fueron poco adecuadas, por lo que desde el propio órgano directivo del orfeón se buscaron nuevas ubicaciones para continuar con la experiencia.

Esa primera experiencia fallida de Virgili sirvió de inspiración a la cúpula dirigente del Orfeó Lleidatà, en la cual se encontraba el matrimonio formado por Ricard Plana (presidente del Patronato Juvenil) y Lluïsa Franch. Dicho matrimonio junto con Virgili, crearon un equipo de trabajo en el que "el matrimonio Plana-Franch, como padres, y Lluis Virgili dando forma a la inspiración de su mundo, Cantarelles d'Estiu, junto con otros colaboradores allanando obstáculos con ilusión, y poniendo incluso algún dinero" (Benseny, 1993, p. 127), hacen posible la creación y organización de las primeras colonias musicales del Orfé Lleidatà en 1968 en el pueblo de Tirvia (Lérida), las cuales son, además, las primeras colonias musicales de España.

Esas Cantarelles d'Estiu (en castellano "cantinelas de verano") tuvieron en sus orígenes tres turnos, dos en julio y uno en agosto, de quince días de duración cada uno. Posteriormente, con el paso de los años, el tercer turno se transformó en un turno hispano-francés, en el que convivían alumnos catalanes con niños del sur de Francia. En todos los casos se finalizaba siempre con un concierto al que acudían sus padres. Dichas colonias se siguen realizando aún en la actualidad.

Para poder entender las intenciones que los organizadores perseguían en esta primera colonia, incluimos parte del discurso de inauguración de la misma, pronunciado por Plana:

Entendemos que las colonias han de ser eminentemente pedagógicas y activamente culturales. Han de influir en las inteligencias de los niños para que comprendan las inquietudes de todo un pueblo.

Esta colonia no es ni la colonia de Lleida, ni la colonia de $l$ 'Orfé. Es la colonia de todo un pueblo que renace y que necesita fortalecerse a través de la inteligencia y de la voluntad, las inquietudes que todos llevamos en el fondo de nuestra alma (Benseny, 1993, p. 127).

Dicho discurso marca la función educativa que tienen las colonias, considerando a las mismas como un contexto formativo que va más allá del simple ocio de los asistentes. De la misma forma, apela al renacimiento de un pueblo, refiriéndose al pueblo catalán, realizando una referencia clara a la permisividad que desde pocos años antes mostró el franquismo ante la lengua y la cultura catalana.

Los resultados obtenidos en Cantarelles d'Estiu en lo referente al alumnado se analizaron desde dos enfoques: por un lado, las relaciones interpersonales creadas entre los asistentes; y, por otro, la evolución musical mostrada por los participantes. De la misma forma, se evaluaban los beneficios que unas colonias podían representar para el resto del personal implicado, concluyendo que aportaban beneficios 
ก้ culturales para Cataluña a la vez que suponían una fuente de - ingresos para los profesores, como se puede apreciar en el $\checkmark$ siguiente texto que reflejan las inquietudes de dichos ल) comienzos:

Apuntamos que una red de colonias musicales representaría una valiosa colaboración para la tarea de culturización del país. Los equipos de profesores tendrían un campo de actividades complementarias en época de ocio, la cual haría más rentable la inversión que supondría la realización del programa que proponemos (VV. AA., 1980, p. 24).

\section{Desarrollo histórico de las colonias musicales}

Esta primera experiencia leridana, catalana y nacional tuvo su repercusión, estuvo supeditada a la evolución que experimentaron las colonias escolares. En este sentido los cambios sociales y educativos influyeron de forma decisiva en la evolución de las colonias, adaptándose estas a las nuevas inquietudes, apareciendo nuevas tipologías de colonias o consolidándose las ya existentes, como es el caso de las musicales.

En este sentido, y especialmente desde la instauración de la democracia, y gracias a una nueva forma de entender la educación en el tiempo libre, los esfuerzos organizativos se encaminaron a cubrir las inquietudes culturales de la población, factor que favoreció las colonias musicales (Calderón y Gustems, 2012). Si bien al tratarse de actividades enmarcadas dentro de la educación no formal y en su origen, de iniciativa privada, resulta muy complicado cercar las diferentes propuestas, sí parece claro que las siguientes actividades similares se siguieron desarrollando en Cataluña. Años más tarde, a partir de 1996, la propuesta de colonias musicales se extendió por el resto del estado, cambiando, en la mayoría de los casos, la terminología de "Colonia" por otra que respondía principalmente a criterios publicitarios. Incluimos la siguiente tabla en la cual se puede observar el año de inicio y lugar de las principales colonias musicales a nivel de toda España:

\begin{tabular}{|c|c|c|}
\hline Año & Colonia & Localidad \\
\hline 1968 & Cantarelles d'Estiu & Tirvia (Lérida) \\
\hline 1975 & $\begin{array}{l}\text { Colònia musical de Jordi } \\
\text { Turull }\end{array}$ & Barcelona \\
\hline 1980 & Colònia d'Estiu de Banyoles & Bañolas (Gerona) \\
\hline 1984 & $\begin{array}{l}\text { Colònia musical de Castellar } \\
\text { de N'Hug }\end{array}$ & $\begin{array}{l}\text { Castellar de Nuch } \\
\text { (Barcelona) }\end{array}$ \\
\hline 1985 & Ai Bandis Musicandis & Gerona \\
\hline 1986 & $\begin{array}{l}\text { Les Colònies Musicals i curs } \\
\text { de Música per a joves }\end{array}$ & Barcelona \\
\hline 1987 & Campus musical a Freser-Ter & Ripoll (Gerona) \\
\hline 1987 & $\begin{array}{l}\text { Colònia musical de Sant } \\
\text { Cugat del Vallès }\end{array}$ & $\begin{array}{l}\text { San Cugat del Vallés } \\
\text { (Barcelona) }\end{array}$ \\
\hline 1987 & $\begin{array}{l}\text { Colònia musical de l'Escola de } \\
\text { Música del centre de Lectura } \\
\text { de Reus i del Centre de } \\
\text { Difusió Musical de Tarragona }\end{array}$ & Tarragona \\
\hline
\end{tabular}

\begin{tabular}{|c|c|c|}
\hline Año & Colonia & Localidad \\
\hline 1996 & $\begin{array}{l}\text { Les estades de Música de } \\
\text { l'Estiu és teu }\end{array}$ & $\begin{array}{l}\text { Espluga de Francolí } \\
\text { (Tarragona) }\end{array}$ \\
\hline 1996 & Camp Musical & Ibiza \\
\hline 1997 & $\begin{array}{l}\text { Academia de Verano de } \\
\text { Música de Graus }\end{array}$ & Graus (Huesca) \\
\hline 2000 & $\begin{array}{l}\text { Campamento musical Torre } \\
\text { de Alborache }\end{array}$ & Villarreal (Castellón) \\
\hline 2002 & $\begin{array}{l}\text { Les Colònies per a Joves } \\
\text { Intèrprets Folk }\end{array}$ & $\begin{array}{l}\text { Bellver de Cerdaña } \\
\text { (Lérida) }\end{array}$ \\
\hline 2002 & Campamento Flauta Mágica & Málaga \\
\hline 2003 & $\begin{array}{l}\text { Muvicamp (Música } \\
\text { Villamayor Campamento) }\end{array}$ & Villamayor (Cáceres) \\
\hline 2004 & $\begin{array}{l}\text { Campamento de Inglés, } \\
\text { Música y Naturaleza "Ad } \\
\text { libitum" }\end{array}$ & Riópar (Albacete) \\
\hline 2004 & $\begin{array}{l}\text { Campamentos musicales de } \\
\text { Villalbín }\end{array}$ & Ureña (Valladolid) \\
\hline 2004 & $\begin{array}{l}\text { Curso-Campamento "Música } \\
\text { y Mar" }\end{array}$ & $\begin{array}{l}\text { El Puerto de Santa } \\
\text { María (Cádiz) }\end{array}$ \\
\hline 2005 & A 12 Cordes & Tirvia (Lérida) \\
\hline 2005 & $\begin{array}{l}\text { Les colònies Musicals } \\
\text { Puigpardines }\end{array}$ & Palafrugell (Gerona) \\
\hline 2005 & $\begin{array}{l}\text { Curso de Orquesta y Música } \\
\text { de Cámara }\end{array}$ & $\begin{array}{l}\text { Itinerante por diversos } \\
\text { municipios de Asturias y } \\
\text { Castilla y León }\end{array}$ \\
\hline 2007 & $\begin{array}{l}\text { Curso Musical de Técnica e } \\
\text { Interpretación Valencia de } \\
\text { Don Juan }\end{array}$ & $\begin{array}{l}\text { Valencia de Don Juan } \\
\text { (León) }\end{array}$ \\
\hline 2007 & $\mathrm{Al}$ son del Molino & Arlanzón (Burgos) \\
\hline 2009 & Rockcamp & Navaleno (Soria) \\
\hline 2010 & Colonia Musical de Solórzano & Solórzano (Cantabria) \\
\hline 2011 & $\begin{array}{l}\text { Les Colònies Musicals de Can } \\
\text { Pere }\end{array}$ & Barcelona \\
\hline 2012 & $\begin{array}{l}\text { Colonias musicales y curso de } \\
\text { música moderna y flamenco } \\
\text { de Villarubia de los Ojos }\end{array}$ & $\begin{array}{l}\text { Villarubia de los Ojos } \\
\text { (Ciudad Real) }\end{array}$ \\
\hline
\end{tabular}

\section{Tabla 1: Relación de colonias musicales celebradas en} España.

Todas estas propuestas han sufrido desigual suerte, ya que en algunos casos siguen su andadura y en otros finalizaron su actividad. En cualquier caso, podemos hacer una recapitulación de las aportaciones a la educación musical y de sus características a lo largo de estas últimas décadas:

- Consolidación de los espacios apartados de las grandes ciudades para la realización de las colonias musicales, dato compartido con las colonias de otras tipologías. 
- Una progresiva disminución de la duración, dato compartido con las colonias de otras tipologías. En el caso de las colonias musicales se ha pasado de los 15 días en los inicios de Cantarelles d'estiu, a los 10 días de media en la actualidad. La mayoría de las colonias musicales en la actualidad optan por una semana de duración.

- Un progresivo aumento en las actividades e instrumentos musicales ofertados, pasando de las actividades exclusivamente corales a la progresiva inclusión de multitud de instrumentos y diferentes estilos musicales. En la actualidad hay propuestas para instrumentos propios de la música clásica, tradicional, antigua, flamenco y moderna.

- Una mejor adecuación de las actividades de ocio ofertadas a la edad de los participantes, dato compartido con las colonias de otras tipologías. Esto se debe a la progresiva especialización y formación de los monitores de tiempo libre.

- Ampliación de la oferta en lo que respecta a la estructura de las clases, ya que a pesar de que la constante siguen siendo las clases colectivas, algunas colonias han ido incluyendo la oferta de clases individuales de instrumentos.

- Consolidación de los conciertos, tanto los que se realizan como final de la colonia delante de todos los familiares, como los que se realizan en el día a día con la única asistencia de los integrantes de la colonia como público y que se usan para trabajar aspectos relacionados con la actitud escénica.

- Un progresivo cambio en el número de alumnos implicados. Dicho número fue en ascenso hasta el año 2010, llegando hasta un máximo de 2500, iniciándose después un progresivo descenso. Este dato coincide con la creación y posterior desaparición de algunas colonias musicales. En la actualidad podemos hablar de aproximadamente unos 2000 alumnos totales.

- Una progresiva ampliación de la edad de los participantes. En la actualidad en las diferentes colonias musicales tiene cabida alumnado entre los 6 y los 17 años, existiendo colonias que amplían dicha edad e incluyendo la posibilidad de asistencia a mayores de edad. Dicha ampliación ha venido acompañada de una mayor diversificación de los diferentes niveles musicales.

- Una distribución desigual en la ratio alumnos/ profesor, que varía entre 30/1 y 4/1 en función de la colonia que analicemos.

- Al igual que en el número de alumnos, la cantidad de profesores implicados fue en ascenso hasta el año 2010 produciéndose en ese momento un punto de inflexión. En la actualidad existen aproximadamente 145 profesores de música implicados en toda España.

- Una desigualdad en el precio de cada colonia. Este dato se debe a que algunas comunidades autónomas han pasado a subvencionar determinadas colonias musicales, por lo que en la actualidad el coste, en lo que al usuario se refiere, difiere entre los $15 €$ y los $65 €$ diarios.

Además de todo esto, en la actualidad, la mezcla de ocio y música que propician las colonias musicales es adoptada igualmente en las escuelas de música, realizando éstas su propia adaptación y promoviendo fines de semana en una casa de colonias en la que se organizan ensayos de orquestas, bandas y grupos de alumnos de la propia escuela.

\section{A modo de conclusión}

Las colonias musicales surgieron como una evolución de las actividades musicales que se realizaban en las colonias escolares. Dichas actividades se centraban mayoritariamente en el canto coral, que a su vez fue el eje central de la primera colonia musical en 1968 en Cataluña.

Esta actividad pionera se extendió por el resto del territorio nacional surgiendo nuevas colonias en la práctica totalidad de las Comunidades Autónomas. Estas colonias mantuvieron muchas de las características originales, como el aspecto colectivo en lo que se refiere a las clases de música; a la vez que han desarrollado e incluido nuevas características a través de, por ejemplo, una ampliación de la propuesta en lo que se refiere a la oferta de instrumentos.

De la misma forma el número de alumnos, profesores y monitores implicados en esta actividad educativa está ligado a la citada creación de nuevas colonias. En la actualidad podemos hablar de, aproximadamente, 2000 alumnos, 145 profesores de música y 100 monitores de tiempo libre.

En cualquier caso la especificidad y la adaptación que cada colonia presenta según el contexto en el que se realiza, nos permite aventurar un futuro aún más abierto en el que tendrán cabida nuevas posibilidades y tendencias musicales actuales, así como la fusión con nuevas actividades de tiempo libre. Esto garantiza que la conjunción de actividades de ocio con las musicales seguirá presente en los diferentes ámbitos educativos.

\section{Notas}

${ }^{1}$ A lo largo de todo el artículo usaremos preferentemente la expresión «colonia» para referirnos tanto a colonias como a campamentos.

${ }^{2}$ En este sentido no podemos olvidar cómo Rousseau ya propuso la universalización de la enseñanza musical, extendiéndola a todos los ámbitos educativos, enfatizando las actividades vocales y corales a través de canciones simples y no dramáticas que permitiesen la flexibilidad y la uniformidad vocal (Rousseau, 2002).

${ }^{3}$ De hecho Lluís Virgili pertenecía al movimiento coral internacional $A$ coeur Foie surgido en Francia.

\section{Referencias citadas}

Benseny, T. (1993). Tírvia, 25 anys. Cursos internacionales de música, 30 anys. En M. Lladonoda (Director). L'Orfeó Lleidatà/Lluis Virgil,. Lérida: Orfeó Lleidatà.

Bión, W. (1887). Les colonies de vacances. Memorie historique et statistique. París: Ch Delagrave-Hacchette et $\mathrm{C}^{\mathrm{a}}$.

Calderón, D. (2015). Colonias musicales en España. Historia y dimensiones formativas. Tesis doctoral. Barcelona: Universidad de Barcelona. Disponible en http:// hdl.handle.net/2445/61148.

Calderón, D. y Gustems, J. (2012). El desarrollo artístico en las colonias y campamentos de verano. Artseduca, 2, 58-67.

Campos, R. (1995). Higiene y moral en España. Segunda mitad del XIX y principios de XX. Hispania: Revista Española de Historia, 191, 1093-1112.

Estivill i Rius, A. (2013). Las bibliotecas populares de Barcelona como espacios de socialización durante el franquismo, 1957-1975. BID: Textos Universitaris de Biblioteconomía i Documentació, 30. Disponible en http:// bid.ub.edu/es/30/estivill.htm. 
Frente de Juventudes. (1945). Canciones para marchas y campamentos. Tarragona: Frente de Juventudes.

Galí, A. (1979). Història de les institucions $i$ del moviment cultural a Catalunya.1900 a 1936. Llibre II: Ensenyament Primari. Barcelona: Fundación Alexandre Galí.

Guereña, J. L. (1998). De París a Barcelona (1933-1996). El proyecto Sociedades Musicales y Cantantes. En J. Carbonell (Coord.). Els orígenes de les associacions corals a Espanya ( $S$. $X I X-X X)$. Barcelona: Oikos-Tau.

Jou, F. (1933). Colònia infantil. Revista Orfé́ Gracienc, 156, 580.

Luengo, A. (1995). La actividad musical de la Sección Femenina. Tesis Doctoral inédita. Barcelona: Universidad de Barcelona.

Molero, A. (2000). La Institución Libre de Enseñanza. Un proyecto de reforma pedagógica. Madrid: Biblioteca Nueva.

Monroy, A. (1918). Conversaciones pedagógicas. Colonias Escolares. Barcelona: TIP. LIT. M. SIVIT.

Nogués, M. C. (1977). Labor social de la institución. En VV. AA. En el centenario de la Institución Libre de Enseñanza. Barcelona: Tecnos.

Orfeó de Terrassa (1929). L’Orfeó nostre a Saragossa. Gaseta del Orfé Terrassa i del seu grup excursionista, 2(12), 185-199.

Orfeó Lleidatà. (1985). Tírvia (XV aniversari), Cursos Internacionals $i$ altres apunte per a la historia. Lérida: Orfeó Lleidatà.

Orfeó Lleidatà. (2011). 150 años. Orfeó Lleidatà. Lérida: Orfeó Lleidatà.

Pereyra, M. (1982). Educación, salud y filantropía: el origen de las colonias escolares de vacaciones en España. Historia de la educación: Revista interuniversitaria, 1, 145-168.

Rodríguez Pérez, J. F. (2001). Las colonias escolares municipales madrileñas (1919-1936). Tesis doctoral inédita. Madrid: Universidad Complutense de Madrid.

Rousseau, J. J. (2000). El contrato social. Barcelona: Folio.

Rousseau, J. J. (2002). Emilio o la educación. Barcelona: Edicomunicación.

Soler i Borrel, S. (1935). La nostra colònia infantil. Revista Orfeó Gracienc, 174, 896-898.

Tarín, L. (1968). Artur Martorell, maestro de colonias. Barcelona: Servei de Colònies de Vacances, Cáritas.

Terrón, A. (2000). La higiene escolar: un campo de conocimiento disputado. Áreas. Revista Internacional de Ciencias Sociales, 20, 73-94.

Trilla, J., Gros, B., López, F., y Martín, M. (1993). La educación fuera de la escuela. Ámbitos no formales y educación social. Barcelona: Ariel.

Vilariño, O. (1930). La infancia y la naturaleza. Estudio sintético de la influencia que ejercen en el desarrollo orgánico e intelectual del niño, las colonias escolares, los jardines de la infancia y los campos de juego. Madrid: Librería Médica R. Checa y $\mathrm{C}^{\mathrm{a}}$.

VV.AA. (1980). Cultura musical per al poble de Catalunya/Orfeó Lleidatà. Lérida: Fundación Salvador Vives Casajuana. 


\section{Sobre los Autores}

\section{Diego Calderón Garrido (arriba)}

Doctor en Historia del Arte. Titulado superior en música moderna. Es profesor en el Departamento de Didáctica de la Expresión Musical y Corporal de la Facultad de Formación del Profesorado de la Universidad de Barcelona. Trabaja organizando diversas colonias musicales desde hace casi 10 años.

\section{Josep Gustems Carnicer}

Doctor en Ciencias de la Educación. Titulado superior de flauta. Es el director del Departamento de Expresión Musical y Corporal de la Universidad de Barcelona. Investigador en el ámbito de la educación musical. Director de varias tesis doctorales en dichos ámbitos.

\section{Caterina Calderón Garrido}

Doctora en Psicología. Profesora de evaluación psicológica en la Faculta de Psicología de la Universidad de Barcelona. Investigadora en los ámbitos de la psicología clínica y la educación. Directora de varias tesis doctorales en dichos ámbitos.

\section{Diego Galderón Garrido}

Despacho 31 1, Edificio Llevant

Facultad de Educación

Pg. de la Vall d'Hebron, 171.

03035 Barcelona. España.

dcalderon@ub.edu

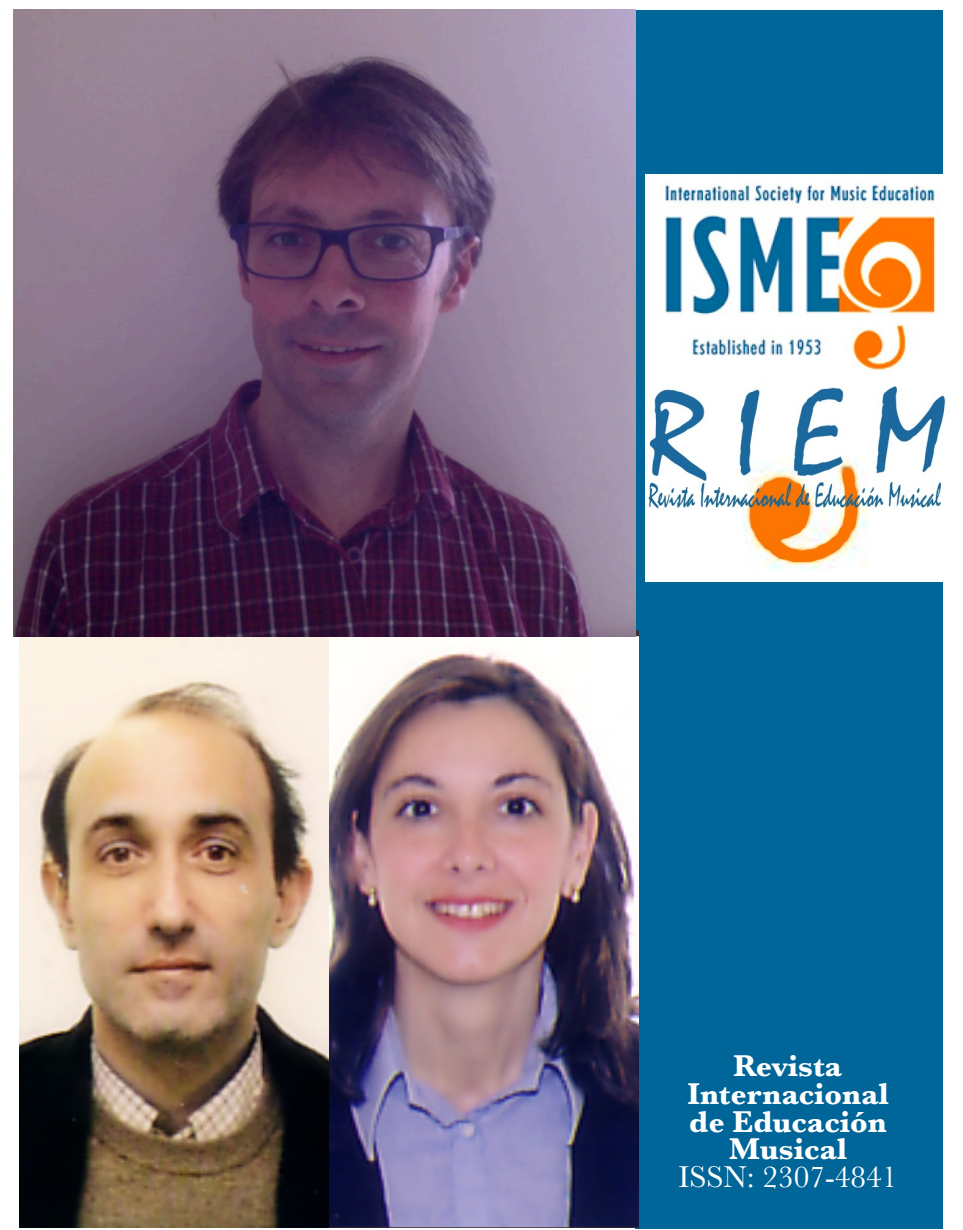

\section{EQUIPO EDITORIAL}

Editor:

José Luis Aróstegui Plaza, Universidad de Granada (España)

\section{Editora Adjunta:}

Rosa María Serrano Pastor, Universidad de Zaragoza (España)

\section{Consejo Editorial}

\section{Carlos Abril, Universidad de Miami (Estados Unidos)}

María del Carmen Aguilar, Instituto Coral de Buenos Aires (Argentina)

Miquel Alsina Tarrés, Universidad de Gerona (España)

Carmen Carrillo Aguilera. Universidad Internacional de Cataluña (España)

Sergio Luiz Figueiredo, Universidad del Estado de Santa Catarina (Brasil)

Patricia Adelaida González, Universidad Autónoma de Chihuahua (México)

Claudia Gluschankof, Instituto Levinsky (Israel)

Josep Gustems Carnicer, Universidad de Barcelona (España)

María Cecilia Jorquera Jaramillo, Universidad de Sevilla (España)

Gotzon Ibarretxe Txakartegi, Universidad del País Vasco (España)

Ana Laucirica Larrinaga, Universidad Pública de Navarra (España)

Ana Lucia Louro, Universidad Federal de Santa María (Brasil)
Isabel Cecilia Martínez, Universidad Nacional de La Plata (Argentina)

Teresa Mateiro, Universidad del Estado de Santa Catarina (Brasil)

María Teresa Moreno, Universidad Laval (Canadá)

Graça Boal Palheiros, Instituto de Educación de Oporto (Portugal)

Jèssica Pérez Moreno, Universidad Autónoma de Barcelona (España) y Universidad de Londres (Reino Unido)

Gabriel Enrique Rusinek Milner, Universidad Complutense de Madrid (España)

Patrick K. Schmidt, Universidad de Ontario Occidental (Canadá)

Favio Shifres, Universidad Nacional de La Plata (Argentina)

Maria dels Àngels Subirats Bayego, Universidad de Barcelona (España)

António Ângelo Ferreira Vasconcelos, Instituto de Educación de Setúbal (Portugal)

Maria Helena Vieira, Universidad del Miño (Portugal)

Gloria Patricia Zapata Restrepo, Universidad de Antioquía (Colombia) 